\title{
Treatment strategy: Role of enfuvirtide in managing treatment-limiting side effects
}

\author{
Christos Tsoukas CM MD FRCP FACP
}

\author{
C Tsoukas. Treatment strategy: Role of enfuvirtide in managing \\ treatment-limiting side effects. Can J Infect Dis Med Microbiol \\ 2007;18(Suppl A):8A-9A.
}

\begin{abstract}
Side effects can limit the options available to physicians for the treatment of HIV infection. Management of these side effects is essential, to avoid cessation of treatment. The entry inhibitor enfuvirtide can be useful as one of three active agents in an HIV treatment regimen as a way to both reduce treatment-limiting side effects and provide an efficacious agent for viral control. In the present case, the patient had a problematic and lengthy treatment history, with numerous concomitant conditions. His latest regimen, which includes an agent in a new drug class (enfuvirtide), has maintained HIV suppression while minimizing toxicity.
\end{abstract}

Key Words: Antiretroviral agents; HIV fusion inhibitors; HIV infection

T reatment-limiting side effects can force clinicians to make less than optimal therapeutic choices in terms of viral control because they try to manage the adverse effects and thereby prevent stopping treatment altogether. Switching off a toxic antiretroviral (ARV) agent to the entry inhibitor enfuvirtide as one of at least three active agents in an HIV treatment regimen can help to reduce treatment-limiting side effects because of enfuvirtide's good safety profile (1). The following case describes how this approach was applied in the management of a patient with a problematic treatment history. During his 11 years of therapy for HIV infection, his treatments have been modified by drug-limiting side effects, as well as concomitant infectious, metabolic, neurological, iatrogenic, allergic, oncological and psychiatric conditions.

\section{CASE PRESENTATION}

The patient, a 61-year-old man, was found to be HIV positive in 1985. At that time, he was also diagnosed with a basal cell carcinoma of the face. He was asymptomatic and did not receive any ARV therapy until 1995, when he began zidovudine (ZDV) and zalcitabine (ddC). His CD4 count at that time was 30 cells $/ \mathrm{mm}^{3}$.

The patient had to stop zalcitabine therapy after six months due to peripheral neuropathy, which caused him to stop working. In 1996, he developed Pneumocystis jiroveci pneumonia, oral candidiasis and a Mycobacterium avium infection associated with generalized lymphadenopathy. He then began a six-month experimental protocol in which he received indinavir monotherapy, and his CD4 count was 10 cells $/ \mathrm{mm}^{3}$. Despite the monotherapy, he had an excellent response to treatment.

In June 1996, his viral load had become undetectable and his CD4 count was 80 cells $/ \mathrm{mm}^{3}$; triple therapy with lamivudine (3TC), indinavir and ZDV was initiated because it was

\section{Stratégie de traitement : Rôle de l'enfuvirtide dans la prise en charge des effets secondaires limitant le traitement}

Les effets secondaires peuvent limiter les options s'offrant aux médecins dans le traitement de l'infection par le VIH. La prise en charge de ces effets secondaires est essentielle afin d'éviter l'arrêt du traitement. L'enfuvirtide, un inhibiteur de la fusion du VIH, peut être utile en tant qu'un des trois agents actifs du traitement antirétroviral. Ce peut être une façon de réduire les effets secondaires limitant le traitement et d'avoir un agent efficace pour le contrôle viral. Dans le cas présent, le patient avait des antécédents de traitements longs et problématiques, avec de nombreuses affections concomitantes. Son dernier schéma thérapeutique en date, qui comprend un agent d'une nouvelle classe thérapeutique, l'enfuvirtide, a maintenu la suppression du VIH tout en minimisant la toxicité.

the standard of care at the time. The following year, he developed depression and osteoarthritis, and by the year 2000, he developed severe peripheral neuropathy.

He continued on the triple therapy regimen until April 2002. His CD4 count progressively increased from 10 cells $/ \mathrm{mm}^{3}$ in 1996 to approximately 500 cells $/ \mathrm{mm}^{3}$ in 2002 . At that point, his HIV-1 viral RNA was undetectable.

To simplify his therapy in April 2002, indinavir was stopped and 3TC plus ZDV was switched to abacavir plus 3TC plus ZDV (Trizivir, GlaxoSmithKline). He subsequently developed an allergy to abacavir, which was complicated by abacavir pneumonitis. All of his ARV medications were then stopped. His CD4 count declined to 165 cells $/ \mathrm{mm}^{3}$ and his viral burden increased to 37,000 copies $/ \mathrm{mL}$.

Between July 2002 and January 2003, treatment with nevirapine and $3 \mathrm{TC}$ plus $\mathrm{ZDV}$ was initiated. However, this treatment was ineffective - his CD4 count continued to decline to 68 cells $/ \mathrm{mm}^{3}$ and his viral burden remained the same. His genotype in December 2002 showed that he had extensive resistance to the nucleoside agents with multiple thymidine-associated mutations (TAMs) and also a G190S mutation, which was consistent with resistance to nevirapine and efavirenz but not delavirdine. In contrast to these genotypic findings for this patient's virus, there appeared to be a lack of mutations to the protease inhibitors.

In March 2003, the patient began taking hydroxyurea (Hydrea, Bristol-Myers Squibb Canada), lopinavir plus ritonavir, delavirdine (Rescriptor, Agouron Pharmaceuticals Canada Inc) and didanosine (ddI), but again he developed an allergy, this time to delavirdine. His CD4 count fell to 42 cells $/ \mathrm{mm}^{3}$ and his viral burden was detectable at 2600 copies $/ \mathrm{mL}$.

Between April 2003 and July 2005, he began treatment with lopinavir plus ritonavir, ddI and $\mathrm{d} 4 \mathrm{~T}$. His viral load

Department of Medicine, McGill University Health Centre, Montreal, Quebec

Correspondence: Dr Chris Tsoukas, McGill University Health Centre, Montreal General Hospital, 1650 Cedar Avenue, Room A5-140, Montreal,

Quebec H3G 1A4. Telephone 514-934-8035, fax 514-937-1424, e-mail chris.tsoukas@muhc.mcgill.ca 
became undetectable at less than 50 copies/mL and his CD4 count increased to 272 cells $/ \mathrm{mm}^{3}$. However, his course was complicated by diarrhea and severe fatigue.

In 2005, the patient developed an anal ulcer, which was subsequently diagnosed as anal carcinoma. He required extensive radiotherapy to control the anal carcinoma.

In July 2005, because of the ongoing diarrhea (not related to radiotherapy), lopinavir plus ritonavir was stopped and he was switched to boosted atazanavir (Reyataz, Bristol-Myers Squibb Canada), which he continued until August 2005. He had to stop all ARV therapy because of lactic acidosis resulting from the combination of ddI and d4T. His CD4 count at that time fell to 120 cells $/ \mathrm{mm}^{3}$ and his viral load increased once more to 37,000 copies $/ \mathrm{mL}$.

He remained off treatment until September 2005, when treatment was reinstituted with lopinavir plus ritonavir, $\mathrm{d} 4 \mathrm{~T}$ and ddI. Atazanavir was not reinstituted. His CD4 count continued to fall to 50 cells $/ \mathrm{mm}^{3}$, but his viral load became undetectable.

He continued to have diarrhea and neuropathy, and for this reason, lopinavir plus ritonavir was stopped, and fosamprenavir (Telzir, GlaxoSmithKline Inc), along with ritonavir $100 \mathrm{mg}$ twice daily, was substituted as of January 2006.

By March 2006, the patient developed lactic acidosis once again because of the ddI and $\mathrm{d} 4 \mathrm{~T}$ combination, although his viral burden remained undetectable and his CD4 count was 78 cells $/ \mathrm{mm}^{3}$. In March 2006, while his HIV RNA was less than 50 copies/mL, the ddI was stopped and replaced by enfuvirtide. The patient remained on fosamprenavir and $\mathrm{d} 4 \mathrm{~T}$, and noted that there was less fatigue, no diarrhea and decreased neuropathy over the next three months. He continued to improve, and by December 2006, his CD4 count had increased to 280 cells $/ \mathrm{mm}^{3}$ and his viral load remained undetectable. His HIV drug resistance genotype remained unchanged over time.

It should be noted that this patient was very compliant with his initial highly active ARV therapy over the six years, despite previous complicated therapies that included three times daily dosing. His problems began with his physician's attempt to simplify therapy and with the unfortunate occurrence of multiple allergies to his ARV medication. The relative lack of options with nucleoside inhibitors led to the continuation of the neurotoxic combination of ddI and $\mathrm{d} 4 \mathrm{~T}$, which also resulted in lactic acidosis, a serious complication of this drug combination. Despite the fact that the HIV infection was controlled with a combination of fosamprenavir, ritonavir, ddI and d4T, the ability to maintain such therapy was compromised by recurrence of lactic acidosis, persistence of neuropathy and diarrhea. The use of enfuvirtide in this situation as a replacement for one of the toxic agents led to an improvement in the patient's overall health by reductions in both diarrhea and neuropathy, as well as absence of lactic acidosis.

Replacement of $\mathrm{d} 4 \mathrm{~T}$ in this patient's treatment regimen is also planned to prevent the ongoing, long-term complications of this nucleoside.

\section{COMMENTS}

The treatment and medical history experienced by this individual is not unusual for patients older than 50 years who have been infected with HIV for an extended period. His treatment was started late in the disease, increasing the likelihood of complications, including cancer. The switches to new treatments, with varied reasons for the changes, were part of an ongoing attempt to achieve virologic control. The decision to simplify therapy was ill advised in retrospect, but the link between inadequate viral suppression and resistance was not as clear as it is now. In this complex mix, the patient's most recent therapy has proven to be the least toxic and most effective. This case illustrates how the addition of a new class of drug that is active against a new target has maintained HIV suppression while minimizing toxicity. The case also points out that enfuvirtide, although administered by injection and used in a patient with less than 50 copies/mL of HIV RNA, has been shown to provide further benefit because of its lack of systemic toxicity.

\section{REFERENCE}

1.Trottier B, Walmsley S, Reynes J, et al. Safety of enfuvirtide in combination with an optimized background of antiretrovirals in treatment-experienced HIV-1-infected adults over 48 weeks. J Acquir Immune Defic Syndr 2005;40:413-21. 


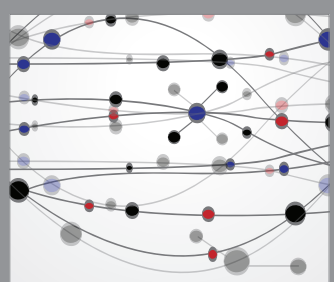

The Scientific World Journal
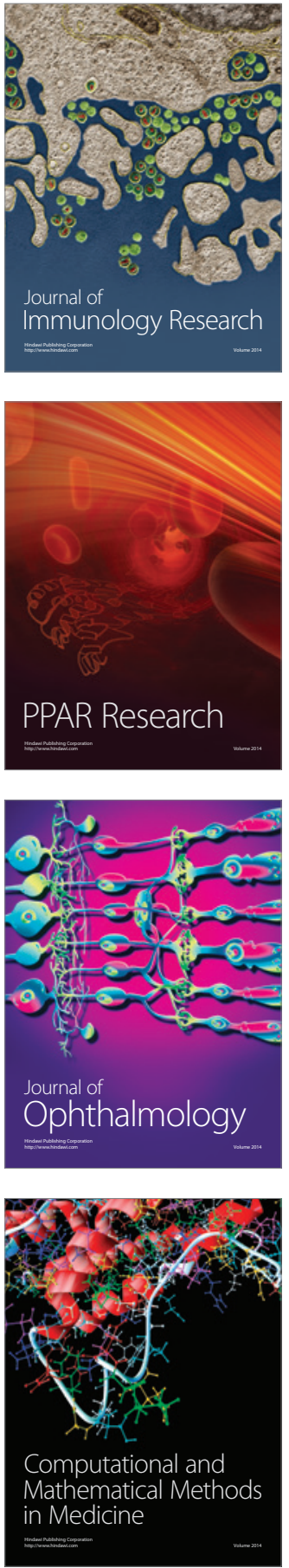

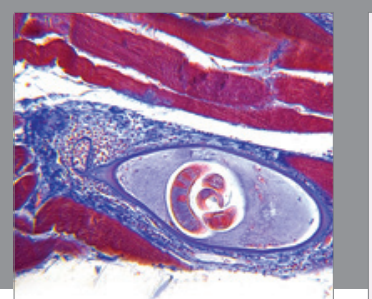

Gastroenterology Research and Practice

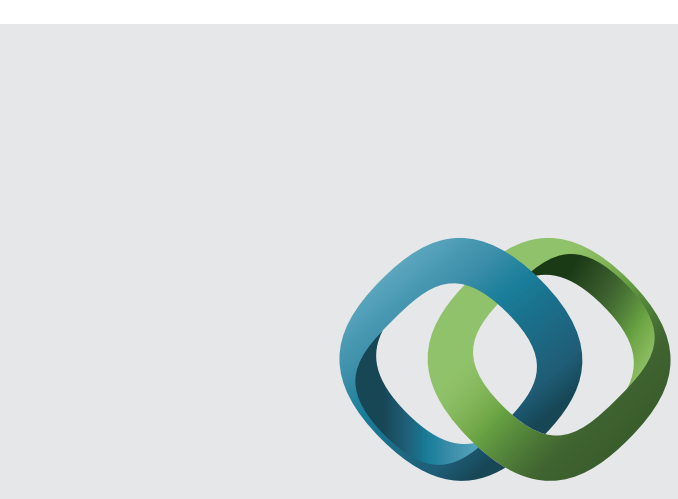

\section{Hindawi}

Submit your manuscripts at

http://www.hindawi.com
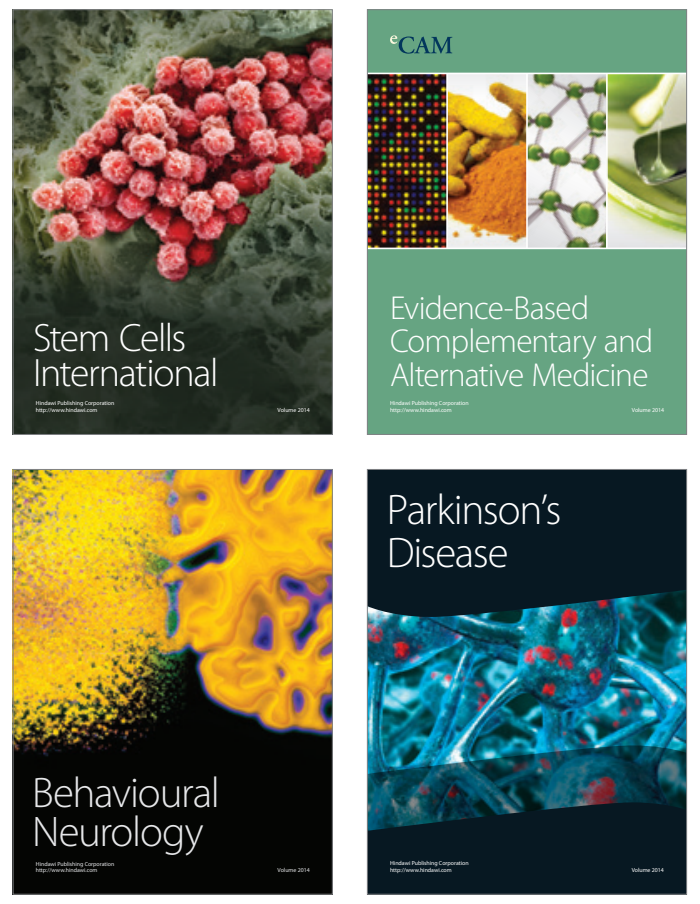
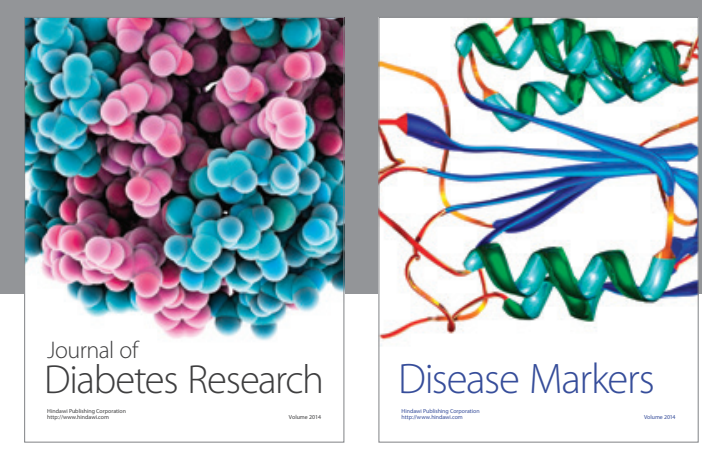

Disease Markers
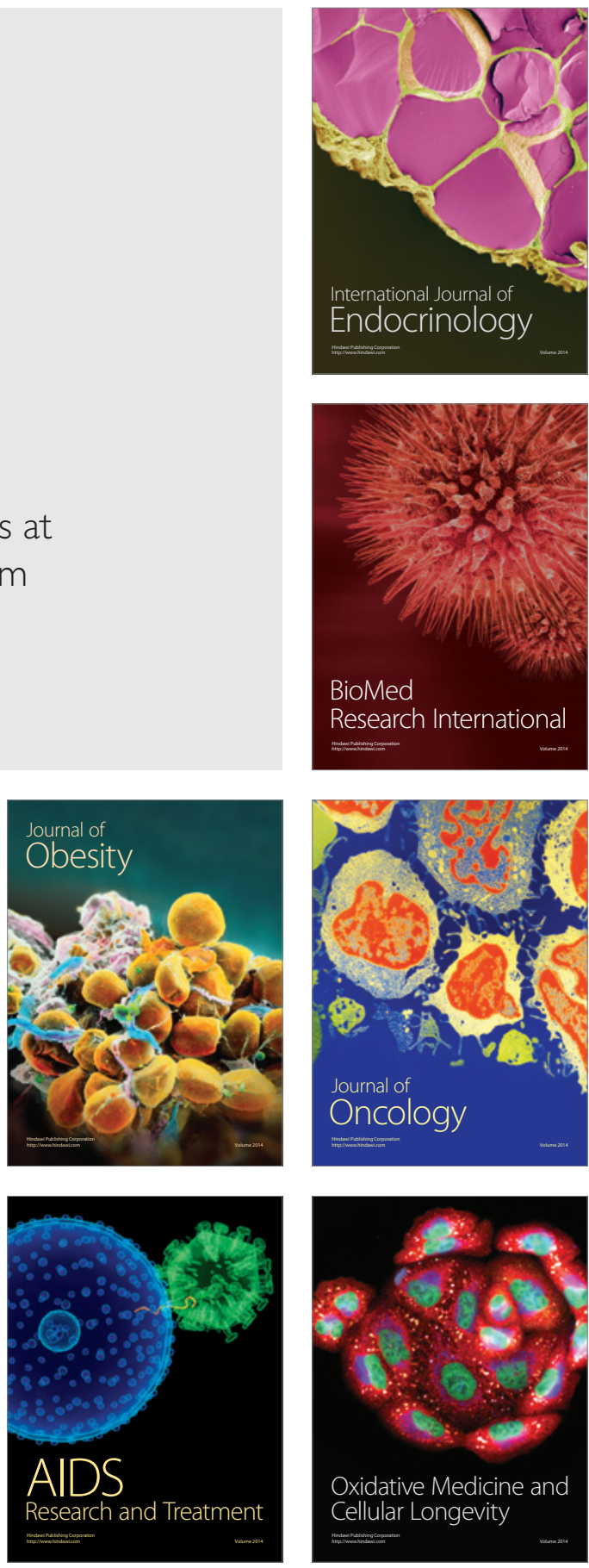